\title{
A LIBERDADE E O ESTADO DE EXCEÇÃO EM TEMPOS DE VIGILÂNCIA
}

\author{
Verônica Vilasboas Amaral" \\ Marcus Antônio Assis Lima ${ }^{* *}$ \\ Argus Romero Abreu de Morais**
}

RESUMO: Este artigo pretende analisar como a liberdade, a vigilância e o estado de exceção transitam na sociedade. A liberdade total não existe, pois, a vivência em sociedade pressupõe o seguimento de regras e leis. Uma forma de vivenciar esta liberdade é através da privacidade, entretanto, com a internet e as redes sociais a privacidade está cada vez mais rara, pois o próprio indivíduo abdica de parte da privacidade em prol da "cultura" do compartilhamento. Neste contexto, a modernidade líquida foi conceituada por Bauman para explicar a rapidez das relações sociais e da tecnologia da atualidade, onde a vigilância é um ponto de convergência, porque ela também se tornou líquida e tem por objetivo o controle social e a manutenção da segurança. O estado de exceção, proposto por Agamben, surge como resposta a um conflito, promove o cerceamento de liberdades individuais com a pretensão de defender a democracia.

PALAVRAS-CHAVE: Liberdade; Vigilância, Estado de exceção.

\section{Liberdade e segurança: um paradoxo humano}

Entre as palavras que são difíceis de conceituar, "liberdade" é uma delas. Assim começa a reflexão do sociólogo polonês Bauman (1989). Por ser uma palavra tão comum no cotidiano, muitas vezes não paramos para analisar de forma aprofundada o seu significado. Por exemplo, a expressão "nós vivemos em um país livre” faz parte do senso comum

\footnotetext{
* Mestranda do Programa de Pós Graduação Letras: Cultura, Educação e Linguagens - PPGCEL da Universidade Estadual do Sudoeste da Bahia (Uesb).

** Doutor em Estudos Linguísticos pela Universidade Federal de Minas Gerais (UFMG). Professor Titular da Universidade Estadual do Sudoeste da Bahia (Uesb).

${ }^{* * *}$ Doutor em Letras pela Universidade Federal de Minas Gerais (UFMG).
} 
e determina que tanto o indivíduo quanto o país que ele reside são supostamente livres. Se não nos aprofundarmos e fizermos questionamentos, o sentido se encerra com a significação acima. Mas que tipo de liberdade é esta?

Bauman (1989) afirma que nós não percebemos que as nossas convicções estão atreladas à sociedade em que vivemos. Esta convivência em comunidade é regida por determinadas leis que instituem os direitos e deveres do indivíduo e o faz responsável por suas ações. Esta experiência segue determinados padrões, o autor sugere a existência de certa regularidade na sociedade, entretanto, se o indivíduo é livre, como é explicada esta regularidade? Quais as condições que devem ser reunidas para que indivíduos livres sigam uma determinada direção?

Uma pressão externa, segundo Bauman (1989), seria responsável por limitar a vontade individual a partir de duas frentes. A primeira é a "coação externa", um elemento da realidade exterior capaz de determinar se a ação do indivíduo é possível ou não. O sujeito é livre para agir, mas se sua ação não estiver de acordo com o poder estabelecido, não poderá ser concretizada. A segunda corresponde à força regulamentadora que é interiorizada pelo indivíduo, que poderia ser chamado de ideologia ou tradição. Estas duas vertentes são responsáveis pela regularidade da sociedade, pois o indivíduo age de acordo com as limitações impostas pela pressão externa.

Bauman (2011) cita Freud ao escrever que a civilização é uma troca, damos algo de determinado valor e recebemos algo de outro valor. Ele demonstra esta premissa com a relação entre segurança e liberdade, quando o indivíduo tem mais liberdade, ele abre mão de parte da sua segurança e, quando tem mais segurança, ele entrega parte da sua liberdade. A liberdade sem segurança é tão ameaçadora quanto a segurança sem liberdade. Esta tensão entre dois polos opostos deve ser suplantada com a tentativa de manter o equilíbrio, pois as duas são essenciais para a vida em sociedade. O autor reforça a importância do equilíbrio entre os dois, ao afirmar que "segurança sem liberdade é escravidão e liberdade sem segurança é um completo caos", entretanto nenhuma sociedade na história conseguiu o equilíbrio perfeito entre os dois. 
Bauman (1989) considera, ainda, que a liberdade tem relação estreita com o individualismo, a economia de mercado e o capitalismo. O individualismo é marcado por duas nuances, aquele que é natural do indivíduo e o que tem que ser legislado pelas autoridades em nome do bem estar comum, com a ressalva de que o ser humano não pode ser visto fora da sociedade; por mais independente que ele seja, dependerá em maior ou em menor grau dos recursos sociais.

O conceito de liberdade se torna mais claro quando a opressão é experimentada, então determinados tipos de liberdade são almejados de acordo com as coerções sofridas. A liberdade total não pode ser vivenciada, pois vivemos em sociedade e ela é regida por leis e regras sociais em sua organização. Se a liberdade total não é possível de ser experimentada, Bauman (1989) sugere, contudo, que uma forma mais tênue desta experiência é a privacidade. Através da privacidade, o indivíduo pode fazer determinadas coisas, em determinados lugares, sem ser observado. Esta privacidade não pode ser total, porque os indivíduos se relacionam socialmente, mas ela pode ser cerceada em ambientes como prisões, hospitais e clínicas psiquiátricas, por exemplo.

\section{O tênue limiar entre o público e o privado}

O público e o privado estão cada vez mais homogêneos, e por isso é difícil distinguilos. Em uma entrevista, Bauman (2011) disse que colocamos microfones nos confessionários, isso significa que a nossa privacidade tem sido exposta nas redes sociais, por nós mesmos ou por outras pessoas. Nossa imagem é gravada por vídeos presentes em condomínios, ruas, lojas, prédios governamentais; o Google grava nossas buscas na internet para nos direcionar para propagandas específicas; no Facebook, é comum tornarmos público o que antes estava na esfera do privado.

A vigilância também é uma forma de aumentar o alcance da publicidade e, por conseguinte, do consumo, sites como a amazon, o google e o facebook monitoram os usuários e, de acordo com suas buscas pela internet, os direcionam para publicidades personalizadas. Esta coleta de dados permite a criação de perfis de consumo para cada indivíduo e exclui aqueles 
que não têm poder aquisitivo. As empresas comerciais, assim como as agências militares, buscam as tecnologias mais avançadas para a coleta de dados e categorização dos indivíduos, um com o intuito comercial e o outro, com o militar (BAUMAN, 2014).

Além desta monitoração exterior, existe também o que nós publicamos em redes sociais, aspectos da vida cotidiana que antes eram restritas ao conhecimento do círculo de pessoas mais próximas, que antes estavam na esfera do privado e que têm cada vez mais se tornado público através de ferramentas virtuais como o facebook e o instagram. Perdemos o nosso direito à privacidade por vontade própria, ou talvez seja o preço pago pela constante vontade de publicar e compartilhar. Nesta sociedade confessional, a regra é compartilhar fotos, detalhes íntimos, textos, vídeos, curtir e compartilhar as publicações, exteriorizar seu estado civil. No lado oposto deste caminho estão as pessoas que preferem manter o anonimato, que ainda sentem a necessidade de resistir a este comportamento que tem se tornado um padrão.

O que antes era privado, agora é público e está disponível para ser consumido por pessoas ávidas e curiosas em saber a vida alheia, e ficará disponível sempre, pois é eternizado na internet. Bauman (2014) sintetizou de forma clara a contradição que a espionagem exerce, o que antes era visto como algo negativo, "nunca estou sozinho”, se configurou em um alívio, "nunca mais vou ficar sozinho":

Creio que o aspecto mais notável da edição contemporânea da vigilância é que ela conseguiu, de alguma maneira, forçar e persuadir opositores a trabalhar em uníssono e fazê-los funcionar de comum acordo, a serviço de uma mesma realidade. Por um lado, o velho estratagema pan-óptico ("Você nunca vai saber quando é observado em carne e osso, portanto, nunca imagine que não está sendo espionado") é implementado aos poucos, mas de modo consistente e aparentemente inevitável, em escala quase universal. Por outro, com o velho pesadelo pan-óptico ("Nunca estou sozinho") agora transformado na esperança de "Nunca mais vou ficar sozinho" (abandonado, ignorado e desprezado, banido e excluído), o medo da exposição foi abafado pela alegria de ser notado. (BAUMAN, 2014, pág. 21). 
$\mathrm{O}$ ato de ser observado era visto como uma ameaça à privacidade, à individualidade; com a ressignificação dada pelas redes sociais, ser observado e, por conseguinte, notado, se transformou em desejo. Estar visível significa ser observado, e é encarado como reconhecimento social. Enriquez (2004, p.49), sociólogo tunisiano, disse que "a nudez física, social e psicológica está na ordem do dia". A internet transformou de maneira significativa a relação que as pessoas têm com elas mesmas e com a sociedade. Se tornar visível através das redes virou regra, ninguém quer ser ignorado e esquecido, por isso, as atualizações nas redes são necessárias para abarcar este viés subjetivo e um tanto egocêntrico do indivíduo.

A transformação tecnológica além de provocar uma mudança social, econômica e política, também suscita questões éticas, que, muitas vezes, ainda não são abarcadas pelas jurisdições dos países. Vivemos em um mundo de controle, observação, checagem, uma vigilância constante. $\mathrm{O}$ fato de a vigilância abranger o cotidiano dos indivíduos, faz com que seja necessário pensar e refletir sobre as implicações éticas envolvidas neste processo. É visível que os corpos têm sido utilizados como dados informatizados, através de scaners de leitura óptica ou biométrica, que estão presentes em clínicas, escolas, bancos, aeroportos, entre outros, que visam identificar o indivíduo e posteriormente permitir ou não o acesso ao local desejado.

\section{Vigilância: o "olhar da ordem" sobre os indivíduos}

O século XX se destacou pela tentativa, segundo Bauman (2014), de modernizar o Estado. Esta tentativa de construção da ordem, de estruturar uma certa disciplina em meio ao caos, de modernizar as organizações de forma obsessiva e ordenar os indivíduos, tinha por finalidade o progresso, e tudo que fosse contrário a esta lógica deveria ser eliminado. Este viés desencadeou efeitos colaterais que assombraram a Europa, e, por conseguinte, teve consequências em todo o mundo. Esta ordem era submissa à infalível norma da razão. Este modelo de razão considerou a diversidade e a divergência de pensamento como algo a ser suprimido através de manipulações comportamentais. A vigilância universal proposta 
por Jeremy Bentham no século XVIII e retomada por Michel Foucault no século XX considerou como padrão desta nova ordem social o poder e a dominação.

$\mathrm{O}$ apogeu aconteceu no início do século XX, a chamada era moderna clássica, com o intuito de alcançar a perfeição, tudo que era diferente deveria ser eliminado, inclusive os seres humanos que não se adequavam ao sistema. Por causa desta constante, foi uma era de destruição que culminou na Segunda Guerra Mundial. Tudo que era imperfeito deveria ser excluído em prol da busca incessante pela perfeição. O sonho do regime cuja excelência seria determinante para não precisar de nenhum ajuste esbarra em dois exemplos que são ilustrativos pela gravidade dos fatos: os casos nazista e stalinista.

O pensamento de colocar ordem no mundo através do poder se concretizou com o partido nazista alemão, na figura do Führer Hitler. Nesta mesma época, ideias semelhantes surgiam também na Europa, com o comunismo totalitário. Os dois modelos tentaram erradicar qualquer elemento que fosse contrário ou resistente ao controle, e, para obter esta finalidade, a modernização e a destruição caminhavam juntas. Os nazistas tentaram redefinir a Europa no contexto político, social e étnico, o radicalismo foi marcante com a deportação de pessoas e posterior envio aos campos de concentração. Sobre este assunto, Bauman (2014, pp. 75 E 78) pondera:

Os autores das maiores distopias de outrora, como Zamyatin, Orwell ou Aldous Huxley, descreveram suas visões dos horrores que assombram os habitantes do mundo sólido moderno: um mundo de produtores e soldados estritamente regulados e maníacos pela ordem. Colocados sob alerta vermelho, esperavam que essas perspectivas chocassem seus companheiros de viagem rumo ao desconhecido, sacudindo-os do torpor de ovelhas marchando com humildade para o abatedouro. Será esse o nosso destino, avisavam eles, a menos que vocês se revoltem. (...) Muitas vezes as distopias se transformam em profecias que refutam a si mesmas, como pelo menos sugere o destino das visões de Orwell e Zamyatin.

Bauman (2014, p.61) cita uma descrição que George Orwell fez a respeito da Segunda Guerra Mundial: "Enquanto escrevo, seres humanos altamente civilizados estão voando sobre mim, tentando me matar. Eles não têm inimizade em relação a mim como 
indivíduo, nem eu em relação a eles. Estão apenas 'fazendo o seu trabalho', como se diz." Com o advento de tecnologias mais avançadas, o que Orwell descreve se tornou muito mais patente, pois com a substituição parcial do indivíduo pela máquina, ocorreu um maior distanciamento e, portanto, uma menor interferência moral e emocional, que, por serem atitudes tipicamente humanas, não estão presentes nas máquinas:

No início do século XXI, a tecnologia militar conseguira fazer a responsabilidade flutuar, e portanto "despersonalizá-la" num grau inimaginável no tempo de Orwell ou Hannah Arendt. Mísseis ou drones (aeronaves não tripuladas) "espertos”, "inteligentes”, assumiram o processo de tomada de decisão e a seleção dos alvos, confiscados tanto dos soldados rasos quanto dos membros dos mais altos escalões na máquina militar. Eu sugeriria que os desenvolvimentos tecnológicos mais fundamentais dos últimos anos não foram pesquisados e introduzidos para aumentar o poder mortífero dos armamentos, mas na área da "adiaforização" da matança militar (ou seja, sua exclusão da categoria de ações sujeitas à avaliação moral). (BAUMAN, 2014, p. 62)

Fazendo um paralelo com o que acontece na atualidade, Bauman (2014) considera que as atrocidades cometidas pelos nazistas ainda ocorrem nos dias de hoje, com a diferença de serem mais diluídas e automáticas por conta da intermediação da tecnologia a partir da "ausência, distanciamento e automação", termo utilizado por David Lyon. Este distanciamento e automação promovem a flexibilização das questões éticas e morais. No caso dos drones, aparelho aéreo não tripulado, controlado remotamente, que possui câmera filmadora e fotográfica acopladas, e é utilizado tanto em guerras quanto para fins pacíficos, ao serem utilizados em uma guerra, por exemplo, se diferenciam de um ser humano, por não possuírem nenhum tipo de ética; um soldado poderia ter compaixão por uma determinada pessoa, o drone é uma máquina, simplesmente executa as tarefas programadas em seu sistema.

Outra questão relacionada ao drone e que também diz respeito ao aspecto moral, são os desdobramentos da execução de uma tarefa. O drone é responsável por localizar e 
colher informações do alvo escolhido em tempo real, se por acaso ocorrer um erro, e pessoas inocentes morrerem, a culpa poderá ser atribuída à máquina, ou seja, este deslocamento de responsabilidade moral permite isentar o indivíduo do crime cometido.

A vigilância física existe e ainda é presente, mas foi superada do ponto de vista do alcance pelas ferramentas eletrônicas, como, por exemplo, o próprio drone, ou o banco de dados, que a partir da internet é capaz de saber as escolhas de determinando indivíduo ou grupo, a partir das suas pesquisas online, ou das suas compras no cartão. Este distanciamento propiciado pelas ferramentas eletrônicas, que, além de físico, pode ser também jurídico, faz com que haja também um distanciamento moral.

O conceito de modernidade líquida foi teorizado por Bauman (2001) para explicar a atualidade, ele utilizou a metáfora do líquido para demonstrar a velocidade e a efemeridade das relações sociais e humanas, onde as formas sociais se desintegram mais rapidamente do que se constroem novas. A velocidade e a dinamicidade fazem parte desta modernidade, "vivemos em um tempo líquido, nada é feito para durar" (BAUMAN, 2001, p.16). Com esta nova dinâmica, outro aspecto que se tornou líquido foi a vigilância. Antes restrita, a vigilância tem se ramificado por diversos setores da sociedade. Bauman (2014) considera que a sociedade moderna tem por finalidade a manutenção da ordem social e, para conseguir o controle social e garantir a segurança, medidas de vigilância são utilizadas para monitorar os indivíduos.

David Lyon (1998) classifica a vigilância na internet em três segmentos: vigilância pela entidade patronal; vigilância de segurança e policiamento e vigilância com fins comerciais e marketing. A vigilância pela entidade patronal é aquela exercida pelas entidades patronais através da monitoração e supervisão dos trabalhadores através do cartão de ponto ou biometria, do sistema de vigilância e da restrição das atividades online com o bloqueio de sites da internet que não possuem relação com o trabalho. Todas estas medidas têm o intuito de aumentar a produtividade do trabalhador. A vigilância de segurança e policiamento é feita pelo Estado através de políticas de controle e supervisão. O seu emprego se 
acentuou principalmente após os atentados terroristas de 11 de setembro de 2001 nos Estados Unidos, e o intuito deste tipo de vigilância é - supostamente - promover a segurança da população. A vigilância com fins comerciais e marketing é descrita por Lyon (1998) como uma atividade exercida por empresas da internet que têm o intuito de rastrear e analisar dados para criar categorizações de indivíduos de acordo com suas pesquisas online, para posteriormente direcionar campanhas de marketing específicas para cada público.

Por outro viés, a vigilância é justificada como forma de manutenção da segurança, uma maneira de proteger o cidadão, o residente de um condomínio, o aluno de uma universidade, o cliente de uma loja: "vigiar para cuidar", pelas palavras de Bauman (2014). A forma primordial de execução da segurança é feita através das tecnologias de vigilância, entretanto, o alvo não é concreto, está difuso entre as diversas possibilidades, ou as diversas pessoas gravadas pelos equipamentos.

Atrelada à vigilância, a segurança se tornou um desejo de consumo. Além das câmeras, os aparelhos de leitura óptica e biométrica têm se popularizado, pois a segurança é uma busca constante dos governos e dos indivíduos. No livro "Vigilância Líquida", escrito a partir de diálogos entre David Lyon e Zygmunt Bauman, Lyon (2014, p. 9) descreve a gradual separação entre política e poder:

O poder agora existe num espaço global e extraterritorial, mas a política, que antes ligava interesses individuais e públicos, continua local, incapaz de agir em nível planetário. Sem controle político, o poder torna-se fonte de grande incerteza, enquanto a política parece irrelevante para os problemas e temores da vida das pessoas. O poder de vigilância, tal como o exercido por departamentos governamentais, agências de polícia, e corporações privadas, enquadra-se muito bem nessa descrição. Até as fronteiras nacionais, antes geograficamente localizadas - ainda que de modo arbitrário -, agora aparecem, nos aeroportos, distantes das "bordas" territoriais, e, o que é mais significativo, em bases de dados que podem nem estar "no" país em questão.

A finalidade de toda e qualquer vigilância, segundo Bauman (2014, p.64), é "identificar os alvos, localizá-los e / ou concentrar-se neles - toda diferenciação funcional começa nessa base comum". Os sistemas de vigilância instalados em lojas, supermercados, bancos, 
condomínios, prédios públicos e ruas são responsáveis por trazerem mais segurança por supostamente coibirem assaltos e atos de violência, por intermédio de câmeras filmadoras. Além destes, há uma outra forma de monitoramento através de bancos de dados que também é utilizada por muitas instituições públicas e privadas. Banco de dados é uma estrutura organizada de dados que se relacionam e permitem a obtenção de informações, uma de suas funções é a categorização de indivíduos. No caso de lojas, bancos e supermercados, por exemplo, os bancos de dados são utilizados para classificar os indivíduos que são dignos de crédito e os que não são. Este é também um meio de exclusão social do indivíduo, ou com as palavras de Bauman (2014), uma "morte social”. Bauman (2014) faz uma citação do sociólogo escocês David Lyon a respeito das consequências da sociedade de controle no cotidiano do indivíduo:

A cultura do controle vai colonizar outras áreas da vida, com ou sem nossa permissão, por causa do desejo compreensível de segurança, combinado com a pressão a adotar certos tipos de sistemas. Os habitantes comuns dos espaços urbanos, cidadãos, trabalhadores e consumidores - ou seja, pessoas sem ambições terroristas de qualquer tipo-, vão descobrir que suas oportunidades na vida estão circunscritas pelas categorias em que são classificadas. Para alguns, essas categorias são particularmente prejudiciais, restringindo suas chances de consumo em função de avaliações de crédito ou, mais insidiosamente, relegando-os a um status de segunda classe devido à sua cor ou a seus antecedentes étnicos. É uma velha história sob um disfarce bigh-tech. (LYON, 2004, p.297)

Em janeiro de 2017, o presidente do Estados Unidos da América, Donald Trump, assinou um decreto que proíbe a entrada de pessoas oriundas de sete países em solo americano. Cidadãos do Iraque, Iêmen, Irã, Síria, Líbia, Somália e Sudão têm as suas entradas em território norte-americano negadas. Em comum, estes países têm maioria muçulmana, o que reforça o estigma de que todo muçulmano é um potencial terrorista. Esta medida, ao invés de amenizar o problema, tem o efeito inverso, o de provocar mais ressentimento.

A metáfora-chave para a vigilância no Ocidente, segundo Bauman (2014), é o Grande Irmão de George Orwell, que exemplifica o perigo de um governo totalitário que possui o monitoramento total de seus cidadãos, e é uma das formas de exercer controle. 
Porém, a vigilância não diz respeito apenas ao controle social e às novas tecnologias, surgem também questionamentos éticos sobre a privacidade, o anonimato. Somos constantemente filmados, checados e este detalhamento de nossa vida cotidiana é cada vez mais transparente para as organizações de vigilância.

A respeito da vigilância em massa, duas questões relacionadas aos Direitos Humanos são suscitadas, a primeira é que toda pessoa tem o direito de ter sua vida privada e familiar anônimas; o segundo é o dever do Estado proteger este anonimato. Em 1873, o juiz norte-americano Thomas Cooley conceituou a privacidade como "right to be let alone", o direito de estar só. O artigo 12 da Declaração Universal dos Direitos Humanos, de 1942, explicita que "Ninguém sofrerá intromissões arbitrárias na sua vida privada, na sua família, no seu domicílio ou na sua correspondência, nem ataques à sua honra e reputação. Contra tais intromissões ou ataques, toda pessoa tem direito a proteção da lei”. Este direito internacional também consta no Pacto Internacional sobre os Direitos Civis e Políticos, de 1966. Entretanto, apesar de ser um direito internacional, cada país segue suas próprias prerrogativas de acordo com as suas escolhas políticas.

A privacidade é o conjunto de informações acerca do indivíduo, que pode tornar público ou manter na esfera do privado. A Constituição Federal brasileira (1988) também versa sobre a privacidade nos seguintes termos:

Art. $5^{\circ}$ Todos são iguais perante a lei, sem distinção de qualquer natureza, garantindo-se aos brasileiros e aos estrangeiros residentes no País a inviolabilidade do direito à vida, à liberdade, à igualdade, à segurança e à propriedade, nos termos seguintes: $\mathrm{X}$ - são invioláveis a intimidade, a vida privada, a honra e a intimidade das pessoas, assegurado o direito a indenização pelo dano material ou moral decorrente de sua violação.

Para ter acesso a informações sobre o indivíduo, é estritamente necessário que haja o consentimento do mesmo. O Estado só pode coletar dados se estiver amparado pela lei, com a devida supervisão do Judiciário. Como o Estado também tem o dever de proteger a privacidade do indivíduo, ele deve regular as atividades de coleta e armazenamento de dados pessoais, por parte do setor privado, para que a privacidade não seja violada. 
O direito à privacidade está intimamente ligado ao direito à liberdade de expressão, pois se uma pessoa que está sob a ótica da vigilância não pode se expressar de maneira efetiva. Nós mudamos o nosso comportamento quando sabemos que estamos sendo vigiados, por isso que a liberdade de expressão neste caso fica prejudicada. Estado de Direito, privacidade e Direitos Humanos são princípios essenciais da atual sociedade democrática.

\section{Estado de exceção: a segurança suprime a liberdade}

A globalização proporcionou a ampliação de redes de relações tanto econômicas quanto sociais, as quais ensejaram uma interdependência crescente entre todos os países do mundo; algo que afeta um, em teoria, afetará todos. Neste quadro, o sentimento de insegurança se tornou uma constante, uma consequência do efeito colateral, que Bauman (2006) chamou de "globalização negativa", resultado da intensificação do terrorismo, da vigilância, dos crimes, entre outros.

Franklin Rossevelt, presidente dos Estados Unidos, em seu discurso de posse em março de 1933 afirmou que "a única coisa que nós temos que temer é o próprio medo, o terror irracional, injustificado que paralisa esforços necessários para converter o recuo no avanço”. Em um tempo marcado pela presença de carros blindados, cercas elétricas, condomínios fechados, terrorismo, o medo geralmente faz parte do cotidiano das pessoas.

Os países considerados desenvolvidos, que têm as taxas de violência mais baixas se comparadas com os países em desenvolvimento, usufruem de mais segurança, mas, apesar de parecer contraditório, são os que mais se sentem ameaçados, amedrontados e, por conseguinte, mais se preocupam com a segurança. Esta obsessão por segurança é o combustível do medo, da insegurança. O medo além de provocar incertezas também gera um sentimento de ansiedade que faz com que seja natural assumir uma postura defensiva.

Esta vulnerabilidade mundial provocou uma obsessão pela segurança das fronteiras e das populações. A segurança pretendida não pode ser obtida de maneira efetiva em um mundo globalizado. Facilmente a insegurança se torna um sentimento de injustiça se algum acontecimento nocivo ocorre, e logo a vingança pode ser utilizada como "discurso". 
Quando ocorre algum fato negativo, o terrorismo, por exemplo, o chefe de Estado pode instaurar um estado de emergência, o qual pode se transformar em estado de exceção (AGAMBEN, 2004).

O Estado de Direito surgiu no final do século XVIII a partir de um movimento revolucionário liderado pela burguesia, que queria acabar com o absolutismo, cujo modelo político era marcado pela concentração de todos os poderes na figura do déspota. Com o Estado de Direito, houve a separação dos poderes e o governante tinha que se submeter às leis, de modo que o direito passa a organizar a sociedade e a política. A partir deste novo modelo, dois princípios básicos deveriam ser satisfeitos: a proteção das garantias individuais e a limitação do poder do Estado.

O Estado de exceção é uma resposta do governo aos conflitos internos ou externos, como é o caso do terrorismo. Esta prática limita certas liberdades individuais e, de acordo com Agamben (2004), é bastante comum, inclusive, em estados democráticos modernos. Este estado de exceção é um mecanismo que tem a pretensão de defender a democracia, devendo ser um paliativo enquanto houver ameaça aos cidadãos ou à prática política. Depois de solucionado o problema, a democracia deve ser restabelecida. Entretanto, estas ameaças tendem a ser difusas, não sendo possíveis soluções em um breve espaço de tempo; portanto, o que deveria ser provisório, torna-se um paradigma de governo dominante na política contemporânea. Este novo governo, segundo Agamben (2004), está no limiar entre democracia e absolutismo.

O estado de exceção pode ser caracterizado por uma ampliação dos poderes do executivo, que poderia promulgar decretos com força de lei. É um regresso a um estado inicial, no qual não há a divisão dos poderes. Neste caso, o executivo assume parte das atribuições do legislativo, o que demonstra um enfraquecimento da divisão dos poderes. Uma explicação que visa legitimar o estado de sítio é a necessidade, como diz o ditado latino necessitas legen non habet, a necessidade não tem lei, ou seja, quando surge uma necessidade, a lei pode ser suprimida, ou deve ser criada uma nova lei. Em relação a este fato Palliere (1970, p. 168) discorre: 
O conceito de necessidade é totalmente subjetivo, relativo ao objetivo que se quer atingir. Seria possível dizer que a necessidade impõe a promulgação de uma dada norma, porque, de outro modo, a ordem jurídica existente corre o risco de desmoronar, mas é preciso, então, estar de acordo quanto ao fato de que a ordem existente deve ser conservada.

Ao mesmo tempo que o estado de exceção está inserido na democracia e foi instaurado devido a determinada emergência, quando está em vigor, ele em nada se parece com o estado democrático. Se, por um lado, existe em algumas constituições a previsão do estado de exceção, por outro, há também em algumas delas o direito à resistência. Agamben (2004, p.23) cita a Constituição da Itália que prevê: "Quando os poderes públicos violam as liberdades fundamentais e os direitos garantidos pela Constituição, a resistência à opressão é um direito e um dever do cidadão.” Na Constituição Federal da República Alemã também há um artigo na Constituição que versa sobre o tema: "Contra quem tentar abolir esta ordem [a constituição democrática], todos os alemães têm direto de resistência, se outros remédios não forem possíveis" (AGAMBEN, 2004, p.23-4)

Agamben (2004) contabiliza em quais países o estado de exceção é descrito de maneira explícita nas constituições ou em leis e em quais não são. França e a Alemanha explicitam o assunto, já a Itália, Suíça, Inglaterra e Estados Unidos não preveem o assunto em suas respectivas leis. No Brasil, estão previstos na Constituição Federal de 1988 o estado de defesa e o estado de sítio.

Depois do 11 de setembro de 2001, data do ataque terrorista às torres gêmeas do World Trade Center nos Estados Unidos, ocorreu de forma mais acentuada uma corrida em busca de possíveis soluções para combater o terrorismo. Diversos países que também sofreram atentados terroristas, tais como Estados Unidos, Espanha, Inglaterra, França, recorreram às técnicas de vigilância e controle como forma de priorizar a segurança nacional. Em um texto publicado no Le monde diplomatique, Giorgio Agamben descreve como a obsessão por segurança modifica a democracia:

A segurança está entre aquelas palavras com sentidos tão abrangentes que nós nem prestamos mais muita atenção ao que ela significa. 
Erigido como prioridade política, esse apelo à manutenção da ordem muda constantemente seu pretexto (a subversão política, o terrorismo...), mas nunca seu propósito: governar as populações.

Os Estados Unidos instituíram uma nova política de segurança chamada de "Guerra ao Terror”. O governo do então presidente George W. Bush se envolveu em duas guerras, no Iraque e na Palestina. Houve também o crescimento dos chamados órgãos de segurança, em 2002, foi criado o Departamento de Segurança Interna com o objetivo de proteger a população norte-americana contra possíveis atentados terroristas.

Além de aumentar o apoio aos serviços secretos, forças armadas e departamentos de investigação, foi criada em 21 de outubro de 2001 uma lei federal chamada de "Patriot Act', em meio à comoção que os atentados causaram. Esta lei restringe os direitos civis e deveria ser aplicada por um tempo limitado, entretanto ela tem sido prorrogada pelo Congresso de forma contínua. Como parte das medidas, houve uma ampliação do poder dos serviços secretos, que podem interceptar comunicações via telefone ou internet sem a necessidade de mandato judicial. Outra medida é a prisão por tempo indeterminado, na prisão de Guantánamo, do estrangeiro que seja suspeito de terrorismo sem a necessidade de ação judicial.

Em 2015, ocorreram vários atentados terroristas na França, que ocasionaram a morte de 129 pessoas e mais de 300 feridos. Como contraparte ao ocorrido, o governo francês decretou estado de emergência e impossibilitou que as pessoas se reunissem nas ruas para homenagear as vítimas. A filósofa norte-americana Judith Butler estava em Paris durante os atentados e o que ocorreu posteriormente, e em entrevista ao site de notícias Opera Mundi escreveu suas impressões sobre o acontecimento:

Uma liberdade é atacada pelo inimigo; outra é restringida pelo Estado, que defende o discurso do 'ataque à liberdade' pelo inimigo como um ataque à essência do que é a França, mas suspende a liberdade de reunir-se em meio ao luto, e prepara uma militarização ainda maior da polícia

Em outro momento do texto, Butler faz questionamentos a respeito do estado de emergência: "Estaríamos vivendo um momento de luto ou uma submissão a um poder de 
Estado cada vez mais militarizado, de suspensão da democracia?” As pessoas se submetem a perder parte da sua liberdade em troca de mais segurança, e o Estado se aproveita desta premissa para militarizar ainda mais os seus territórios.

A principal arma do terrorismo é espalhar o terror. Além de ser noticiado pela imprensa mundial, os ataques terroristas também são divulgados pelas próprias organizações terroristas, principalmente a Al-Qaeda, na internet. Consequentemente, há um aumento do medo global e a insegurança perante estes acontecimentos. Bauman (2008) sugere que as ofensivas militares no Iraque e Afeganistão não conseguem destruir o terrorismo, pois ele não é uma organização e nem obedece a uma hierarquia, e ao contrário do que pretendem, estas ofensivas contribuem para a devastação de cidades e aldeias, estimulando o aumento da violência destes grupos terroristas. Não adianta aumentar o controle das fronteiras, reforçar a segurança dos aeroportos e portos, a solução, segundo Bauman (2008), é o investimento em educação, e o perdão da dívida externa dos países em desenvolvimento, por parte dos países mais ricos.

A geopolítica mundial tem sofrido mudanças significativas. A "primavera árabe” no Oriente Médio foi marcada por diversos protestos por parte das populações da Tunísia, Líbia, Egito, Argélia, Iêmen, Marrocos, Bahrein, Síria, Jordânia e Omã, que foram as ruas para reivindicarem melhores condições sociais e como consequência desta mobilização conseguiram derrubar vários ditadores. Além destes eventos, a insegurança em territórios palestinos também é uma constante; a intervenção norte americana no Afeganistão e no Iraque; os conflitos separatistas, como, por exemplo, o da Chechênia; a ameaça nuclear da Coreia do Norte, entre outros, somam com a instabilidade provocada pelos atentados terroristas nos Estados Unidos, Europa e Oriente Médio. Toda essa conjectura difunde um sentimento de insegurança nas populações.

Como mecanismo de defesa e perpetuação do poder, surge uma sociedade de vigilância. Bauman (2014) considera que a vigilância seja líquida e circule na sociedade de forma fluida, o que justifica a sua naturalização por fazer parte do cotidiano dos indivíduos e 
passar, muitas vezes, despercebido. Há uma disseminação de políticas, métodos e instrumentos de vigilância facilitados pelas tecnologias e pela sociedade em rede, intermediada pela internet.

\section{REFERÊNCIAS}

AGAMBEN, G. Estado de exceção. São Paulo: Boitempo, 2004.

AGAMBEN, G. Como a obsessão por segurança muda a democracia. Disponível em: $<$ http://diplomatique.org.br/como-a-obsessao-por-seguranca-muda-a-democracia/>. Acesso em 10 jul. 2017.

Artigo XII Ninguém será sujeito a interferência na sua vida privada, na sua família, no seu lar, ou na sua correspondência, nem ataques à sua honra e reputação. Toda pessoa tem direito à proteção da lei contra tais interferências ou ataques. Disponível em: <https://www.direitocom.com/declaracao-universal-dos-direitos-humanos/artigo-12o >. Acesso em 25 jul 2017.

BAUMAN, Z. A liberdade. Lisboa: Editorial estampa, 1989.

BAUMAN, Z. Medo líquido. Rio de Janeiro: Jorge Zahar, 2008.

BAUMAN, Z. Vigilância líquida: diálogos com David Lyon. Rio de Janeiro: Jorge Zahar, 2014.

BUTLER, J. Após atentados, França usa o discurso de 'ataque à liberdade' para aumentar a militarização, diz Judith Butler. Disponível em: <http://operamundi.uol.com.br/conteudo/samuel/42304/apos+atentados+franca+usa + discurso + do + ataque $+a+$ liberdade + para + aumentar + militarizacao + diz + judith + butler.s html>. Acesso em 15 jul. 2017

Recebido em: 27/09/2017. Aprovado em: 13/12/2017. 